\title{
Editorial: Special Issue on Experimental Vibration Analysis
}

\author{
Roger Serra* \\ INSA Centre Val de Loire, Université de Tours, Université d'Orléans, Laboratoire de Mécanique G. Lamé, DivS team, \\ 3 rue de la chocolaterie, 41000 Blois, France
}

Received: 15 December 2017 / Accepted: 15 December 2017

\begin{abstract}
The vibratory analyses are particularly present today in the various fields of industry, from aeronautics to manufacturing, from machining and maintenance to civil engineering, to mention a few areas, which have made this special issue a true need. The International Journal of Mechanics \& Industry compiles a Special Issue on Experimental Vibration Analysis. More than thirty manuscripts were received by the international scientific committee on the 6th congress AVE2016 and only eight papers have been selected after completing a careful and rigorous peer-review process for the Special Issue, which are briefly summarized below.
\end{abstract}

\section{Presentation}

The International Journal of Mechanics \& Industry compiles a Special Issue on Experimental Vibration Analysis and makes a focus on the recent challenging innovation and advances in vibration engineering after the last special issue in 2013 [1]. These analyses are necessary to calculate the modal parameters of a system, a structure $[2-3]$ or a mechanism [4], and the expected response to the given excitation [5] (harmonic, random, shock, etc.). In this way, it can be determined whether a particular system, structure or mechanism will fulfill its intended function; in addition, the results of the dynamic loadings acting on a structure can be predicted [6], such as the dynamic stresses, fatigue life [7] and vibration levels. In fact, the most effective structural parameters on the dynamic response can be determined, so that if any change in the response is required, the structure can be modified accordingly in the most appropriate way [8]. Indeed, the vibration analysis are not a single complementary tool. It is the basis of many powerful techniques, which make possible - for instance - to probe the structures or even the interior of materials during their service, to detect the defects or damages [9] and to follow their evolution in real-time,... The experimental vibration analyses are particularly today present in the various branches of industry, from aeronautics to car manufacturing, from machining and maintenance to civil engineering, to mention a few areas, which have made this special issue a true need.

The 5th French congress "Analyse Vibratoire Expérimentale" (AVE2016 http://ave2016.sciencesconf.org) that took place during 15-17 November 2016 at Blois, France, represents one of the efforts to address the above

\footnotetext{
* e-mail: roger.serra@insa-cvl.fr
}

needs and to stimulate the strong scientific interaction between scientists, researchers, and engineers, involved in the recent developments of experimental analysis of the structures by using dynamics approaches. This event should be considered in a rather broad direction, concerning recent advances on experimental vibratory analysis techniques and the exploitations that can be drawn from those analyses.

The present issue of Mechanics \& Industry comprises a selection of papers presented in specific subjects with the aim to give an overview of the amount and the quality of the more than a thirty submitted works on Modal analysis, vibration-based condition monitoring, damage detection and localization, experimental/numerical combined approach, physical experiments with advanced computational methods investigations, and their various engineering/ industrial applications. Selected papers included in this special issue on Experimental Vibration Analysis have completed a careful and rigorous peer-review process by the international scientific committee. The novel technologies/ methodologies developed and knowledge obtained from this Special Issue would also be mostly applicable for the industrial development.

The Guest Editor trust that this document will contribute to disseminate the current trends and topics of interest in this fascinating and fast growing area, that it will be a valuable tool in your research and professional activity and invite you to join our Community.

The Guest Editor would like to express their sincere appreciation to the considerable contributions of all the authors and reviewers. The Guest Editor would also like to appreciate the kind initiative and instructions of Prof. R. Dufour, the Editor of the International Journal of Mechanics and Industry and the editorial service of EDP Sciences. 


\section{References}

[1] R. Serra, Guest editorial, special issue on experimental vibration analysis, Mechanics \& Industry 14 (2013) 97, https://doi.org/10.1051/meca/2013061

[2] J. Lardiès, G. Bourbon, P. Le Moal, N. Kacem, V. Walter, T.-P. Le, Modal parameter identification of a cmut membrane using response data only, Special Issue on experimental vibration analysis, Mechanics \& Industry 18 (2017) 802

[3] G. Kouroussis, L. Ben Fekih, T. Descamps, Using experimental modal analysis to assess the behaviour of timber elements, Special Issue on experimental vibration analysis, Mechanics \& Industry 18 (2017) 804

[4] C.U. Mba, S. Marchesiello, A. Fasana, L. Garibaldi, Gearbox damage identification and quantification using stochastic resonance, Special Issue on experimental vibration analysis, Mechanics \& Industry 18 (2017) 805

[5] G. Kouroussis, H.P. Mouzakis, K.E. Vogiatzis, Structural impact response for assessing railway vibration induced on buildings, Special Issue on experimental vibration analysis, Mechanics \& Industry 18 (2017) 803

[6] T. Sellami, S. Jelassi, A.M. Darcherif, H. Berriri, M.F. Mimouni, Experimental validation of a numerical 3-d finite model applied to wind turbines design under vibration constraints: trevise platform, Special Issue on experimental vibration analysis, Mechanics \& Industry 18 (2017) 806

[7] B. Colin, Characterization of random Gaussian and nonGaussian stress processes in terms of vibration fatigue, Special Issue on experimental vibration analysis, Mechanics \& Industry 18 (2017) 807

[8] A. Assoumane, E. Sekko, C. Capdessus, P. Ravier, Order tracking using $H \propto$ estimator and polynomial approximation, Special Issue on experimental vibration analysis, Mechanics \& Industry 18 (2017) 808

[9] R. Serra, L. Lopez, New combined wavelet methodology for vibration-based damage detection, Special Issue on experimental vibration analysis, Mechanics \& Industry 18 (2017) 809

Cite this article as: R. Serra, Editorial: Special Issue on Experimental Vibration Analysis, Mechanics \& Industry 18, 801 (2017) 